\title{
KALIGRAFI ISLAM; DARI NALAR SENI HINGGA SIMBOLISME SPIRITUAL
}

\section{Islah Gusmian}

Alumni S2 Pascasarjana LAIN Sunan Kalijaga tabun 2002

ملغص

يناقش هذا البحث نشأة فنون الخطوط العربية وتطورها فى العالم الاسلامى و اذا رجعنا

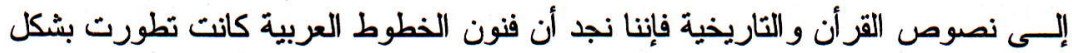
مدهش· وكل هذا بسبب وجود نصوص القرأن و الأحاديث النبوية التى تبين أهمية الكتابة

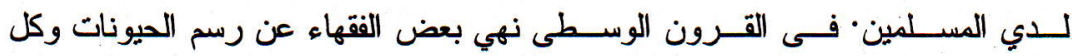

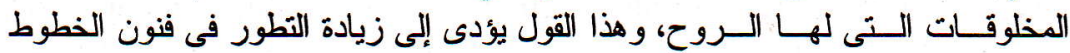

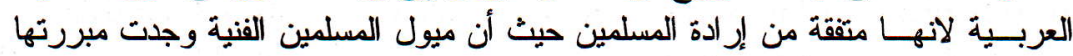

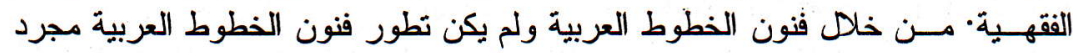

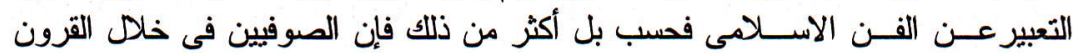

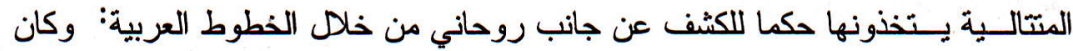

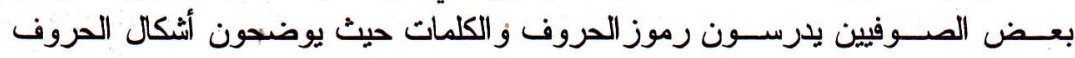

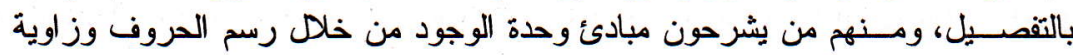

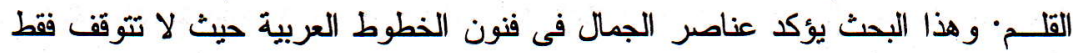

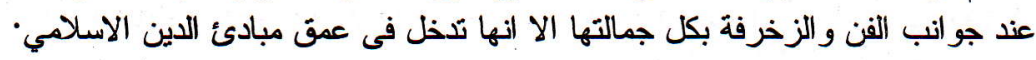

\section{Abstract}

This article reveals the bistory of the rise and the development of calligraphy in Islam. By referring to the bistory and texts of al-Quran, this article shows that Islamic calligraphy bave undergone some significant developments because of the textual effect of al-Qur'an and the al-Sunnab which bighlight the necessity of calligrapby for Muslims. The probibition of drawing living things raised by fuqaba in the medieval age even intensified the development of calligraphy. Then, in its development, Islamic calligrapby is not only an artistic expression of 
Islah Gusmian

Muslims, but, for centuries, the Sufis bave taken the wisdom (bikmab) of spiritual aspects of calligraphy. Some of them talked about the symbols of scripts/letters and words, about the detail shapes of scripts, and some others explained in detail the teaching principle of the existence through the symbols of ink and pen. This article emphasis that the beauty of Islamic calligraphy does not only touch the artistic dimension with all its various type, but also it intertwines intensively with the doctrine of esoteric aspect of Islam.

Keywords: kaligrafi Islam, inspirasi al-Qur'an, karakter huruf, ekspresi seni, simbol spritual

\section{A. Pendahuluan}

Di antara berbagai bentuk tulisan yang berkembang di berbagai bangsa di dunia, tulisan Arab-lah yang mengalami dinamika yang sangat spektakuler dan unik. Karena dalam khazanah tulis-menulis, tulisan Arab dalam perkembangannya tidak hanya sebagai simbol dari suatu bahasa lisan, tetapi telah memasuki wilayah dunia seni dan spiritual. Karakterkarakter khas yang terkandung dalam tulisan Arab dikembangkan sebagai suatu manifestasi simbolik artistik yang sangat indah, sehingga memberikan makna lain di samping makna yang dikandung dalam tulisan itu sendiri. Lewat karakter-karakter tulisan Arab yang khas, para sufi juga membangun metafor-metafor sufistik untuk menggambarkan pengalamanpengalaman spiritualnya.

Pertanyaan yang muncul kemudian adalah, mengapa dalam perkembangannya nuansa-nuansa artistik dan magis begitu kental dalam tulisan Arab, dan mengapa setelah Islam datang wacana tulis menulis di dunia Arab berkembang begitu pesat? Pertanyaan-pertanyaan itulah yang akan ditelusuri dalam kajian ini.

\section{B. Asal Usul Tulisan Arab}

Ungkapan kaligrafi yang selama ini dipakai, berasal dari bahasa Inggris yang disederhanakan: calligraphy diambil dari kata Latin kallos yang berarti indah dan graphein yang berarti tulisan atau aksara. Arti kaligrafi secara utuh adalah kepandaian menulis tulisan elok dan indah, 
dalam Bahasa Arab disebut khat yang berarti garis atau tulisan indah. ${ }^{1}$ Definisi lengkap antara lain dikemukakan Shekh Shamsuddin al-Akfani dalam kitab Irshäd al-Qasid, bab "Ḥaș al-'Ulūm" sebagai berikut:

Khat (kaligrafi) adalah suatu ilmu yang memperkenalkan bentukbentuk huruf tunggal, letak-letaknya dan cara-cara merangkainya menjadi sebuah tulisan yang tersusun. Atau apa yang ditulis di atas garis-garis; bagaimana cara menulisnya dan menentukan mana yang tidak perlu ditulis; menggubah ejaan yang perlu digubah serta menentukan cara menggubahnya. ${ }^{2}$

Ada banyak pendapat mengenai tokoh yang mula-mula menciptakan kaligrafi. Barangkali cerita-cerita keagamaan yang berkembang, yang paling dapat dijadikan pegangan. Para pekabar Arab mencatat Nabi Adam sebagai orang yang pertama kali mengenal kaligrafi. Pengetahuan tersebut datang dari Allah sendiri melalui wahyu. ${ }^{3}$ Inilah barangkali yang dimaksud alQur'an bahwa "Allah mengajari Adam pengetahuan tentang semua nama" seperti yang diterangkan dalam surat Al-Baqarah [2]: 31. Dikisahkan bahwa 300 tahun sebelum wafat, Adam menulis di atas lempengan tanah yang selanjutnya dibakar dan menjadi tembikar. Setelah air surut pasca banjir besar di zaman Nabi Nüh AS, setiap bangsa atau kelompok keturunan mendapatkan tembikar bertulisan tersebut. Dari peristiwa itu kemudian dianggap bahwa setiap bangsa telah mempunyai tulisan sendiri-sendiri. ${ }^{4}$

Dari sebuah Hadith yang diriwayatkan dari Abū Dhar al-Giffari, dapat diketahui bahwa huruf-huruf Arab telah diturunkan untuk pertama kalinya kepada Adam. Terjemahan Hadith tersebut sebagai berikut:

Diriwayatkan dari Abū Dhar al-Giffarì, ia berkata: "Aku bertanya kepada Rasulullah SAW., kataku: "Wahai Rasul, dengan apakah setiap Nabi diutus?"

"Dengan kitab yang diturunkan."

${ }^{1}$ Mircea Eliade, The Encyclopedia of Religion (New York: Macmillian Publishing Company, 1987), hlm. 24-25; D. Sirajuddin AR, Seni Kaligrafi Islam (Jakarta: Pustaka Panjimas, 1985), hlm. 1.

${ }^{2} \mathrm{Abu}$ al-'Abbās Ahmad ibn 'Ali al-Qalqasyandi, Subḥ al-A'shā (Kairo: Wazarah alThaqafah wa al-Irshād al-Qaumi, t.th.), III, hlm. 3-4.

3Ibid., hlm. 6-7.

${ }^{4}$ Sirajuddin AR, Seni Kaligrafi, hlm. 5. 
"Wahai Rasul, kitab apakah yang diturunkan kepada Adam?" "ATif, $b a^{\prime}, t a^{\prime}$, tha' dan seterusnya."

"Wahai Rasul, berapa huruf?"

"Dua puluh sembilan."

"Wahai Rasul, tadi engkau menghitungnya dua puluh delapan."

Lantas Rasul marah sehingga kelihatan merah kedua matanya. Katanya padaku: "Wahai Abu Żar, demi Allah yang mengutusku sebagai Nabi dengan hak! Allah tidak menurunkan kepada Adam kecuali dua puluh sembilan huruf."

"Wahai Rasulullah di dalamnya ada alif dan lam."

"Lam alif itu satu huruf, diturunkan kepada Adam dalam satu sahịfah."

Banyak sejarawan meyakini bahwa yang dimaksudkan oleh Hadith di atas adalah huruf-huruf Arab. Lam alif adalah huruf yang hanya ada dalam alfabet Arab.

Sulit dibuktikan secara historis tentang asal-usul tulisan seperti yang dilansir kisah-kisah keagamaan di atas. Buku-buku sejarah selalu mencatat tentang kaligrafi yang lahir dari ide "menggambar" atau abaaba lukisan yang dipahat atau dicoretkan dalam benda-benda tertentu seperti daun, kulit, kayu, tanah dan batu. Budaya gambar tersebut menyebar luas seperti halnya bahasa. Tetapi tidak berarti bahwa semua gambar mempunyai makna tulisan, sebab maksud gambar 'itu pun bermacam-macam. Hanya gambar-gambar yang dipandang mengandung lambang dan perwujudan dari keadaan tertentu yang diasosiasikan dengan bunyi-bunyi ucap saja yang dapat diusut sebagai bidang pembentukan kaligrafi dan aksara. Dari situ tercipta sistem atau aturan-aturan tertentu untuk membacanya, lalu timbullah cabang ilmu fonetik atau fonologi (makbraj) yang membicarakan struktur bunyi. Di Tiongkok misalnya, dikenal sistem logografika, yaitu tanda-tanda dan gambar-gambar yang dipakai untuk menandai ungkapan-ungkapan kata tertentu dan masih dipakai sampai sekarang. ${ }^{6}$

Semua tulisan atau huruf, sejak yang paling kuno sampai dengan yang sekarang masih dipergunakan, seperti tulisan Mesir Kuno (Pictography, Hieroglyph, Hiearatik), India (Devanagr), Jepang (Kaminomoji),

${ }^{5} I$ bid., hlm. 5-6.

'Ibid., hlm. 6-7. 
Indian (Aqteka), dan Shria (tulisan paku/Fonogram), pada mulanya merupakan tanda-tanda yang sangat sederhana. Setelah ditemukan, tandatanda tersebut disepakati dan dipergunakan oleh generasi yang paling tua sebagai perwujudan ide dan kata-kata mereka dalam bentuk gambar atau lambang yang dapat dilihat oleh mata. Semua lambang itu merupakan bahasa mereka. Kemudian oleh generasi sesudahnya, disempurnakan dengan proses penambahan atau pengurangan sehingga terwujud bentuk tulisan. Demikian juga halnya dengan tulisan Arab.

Menurut penelitian para sejarawan, tulisan Arab yang dipergunakan sekarang ini berasal dari tulisan Mesir Kuno (Hieroglyph) yang terdiri dari g ambar-gambar sehingga disebut Pictograph (tulisan gambar) dan hurufnya disebut Hieroglyph. Karena cara menulis dengan gambar ini tidak ada batasnya, maka kemudian diringkas dengan mengambil dan mempergunakan beberapa huruf Hieroglyiph sebagai huruf yang mempunyai suara tetap. Dari tulisan Heiroglyiph timbul tulisan baru yang disebut Hieratik yang dipergunakan oleh pendeta-pendeta Mesir untuk keperluan keagamaan. Dari huruf Hieratik timbul huruf Demotik yang digunakan terus menerus beberapa ribu tahun hingga abad ke- 5 Masehi. $^{7}$

Dinamika terjadi ketika orang-orang Mesir melakukan perdagangan dengan bangsa Palestina dan Shria. Di utara Palestina, di seluruh pantai Laut Tengah, terutama di lingkungan pegunungan Libanon terdapat suku bangsa Funisia yang masih termasuk bangsa Kan an dan Aremia. Bangsa ini pada awal tahun 2000 SM mendirikan kerajaan yang terbentang dari utara ke selatan Shria. Mereka adalah para pelaut dan pedagang yang mengadakan hubungan dengan Spanyol dan Afrika. Sebagai pedagang yang selalu berhubungan dengan tulis-menulis, mereka kemudian menciptakan tulisan yang berasal dari tulisan Mesir Kuno tersebut. Sesuai dengan nama suku bangsanya, tulisan mereka kemudian dikenal dengan tulisan Funisia (al-Khat al-Fieniceqy). Peristiwa ini terjadi kurang lebih pada tahun 1300 SM. $^{8}$

${ }^{7}$ Abdul Karim Husain, Seni Kaligrafi Khat Naskbi, Tuntutan Menulis Halus Huruf Arab dengan Metode Komparatif (Jakarta: Pedoman Ilmu Jaya, t.th.), hlm. 6; Abu Abdullah alZanzani, Wawasan Baru Tarikh al-Quran, terj. Kamaluddin Marzuki Anwar dan A. Qurtubi Hassan (Bandung: Mizan, 1993), hlm. 37.

${ }^{8}$ Ibid., hlm. 7. 
Suku Aremia dikenal sebagai bangsa Sham Kuno yang bermukim di Shria sekitar tahun 1300 SM. Setelah mengembara sebagai suku yang nomaden dan tergolong bangsa Semit, mereka lalu mendirikan kota Damaskus (Syria). Mereka memiliki bahasa dan tulisan yang lebih sempurna dibanding dengan huruf paku (Sumeria 4000 SM berupa huruf gambar yang terdiri lebih dari 350 jenis suara) dan huruf Mesir Kuno. Menurut penelitian, huruf Aramea ini kemudian menjadi dasar terbentuknya huruf yang lain, di antaranya huruf Brabmi dan Karoshi di India. Huruf Aramea ini didasarkan pada tulisan huruf Funisia. Dari huruf Funisia ini pula kemudian timbul tulisan Musnad yang berasal dari suku Hunain di Yaman. Diduga, tulisan itu disebarluaskan oleh suku Mainiyah (Minaeni) di Yaman yang berpindah ke Arabia Utara. ${ }^{9}$

Dalam perkembangannya, tulisan Musnad berganti bentuk sesuai dengan inovasi suku-suku yang mempergunakannya. Dari tulisan Musnad inilah muncul tulisan Shafawi (akhir abad ke-15 SM), Shamudi (715 SM), dan Libjāini (sebuah kabilah Arab cabang Huzail yang mendiami wilayah timur laut Makkah) di Arabia Selatan dan tulisan Himyari atau Saba'i (Shria) di Arabia Utara. Di antara ciri-ciri bentuk tulisan ini adalah, huruf ditulis dengan terpisah-pisah seperti huruf cetak latin, huruf hidup tidak ditulis, tidak memakai titik, serta kadang-kadang satu huruf dipakai untuk beberapa huruf tanpa diberi tanda perbedaan seperti lazimnya tulisan Arab sekarang. ${ }^{10}$

Setelah itu, masih dari tulisan Musnad ini muncul tulisan Kindi (dari suku Kendah yang mendiami sebelah selatan Arabia Barat Hadramaut awal abad 6 SM) dan tulisan Nabtīi (berasal dari kerajaan Nabaț, yang memanjang dari sebelah selatan Hijaz sampai daerah Shria, yang meliputi daerah-daerah Madyan, selat Aqabah, Hijaz, Palestina dan Huran, abad $1 \mathrm{M}$ ). Kedua tulisan ini dianggap sebagai proses kelanjutan tulisan Musnad yang lebih lengkap dan mencerminkan suku Semit yang paling maju dan berpengaruh besar pada saat itu. Ciri tulisan pada fase ini

\footnotetext{
${ }^{9} I b i d$.

${ }^{10}$ Ibid. Lihat juga, al-Zanzani, Wawasan Baru, hlm. 38.
} 
adalah, huruf sudah ditulis bergandengan seperti sekarang, tetapi masih belum menggunakan titik dan tidak menuliskan huruf-huruf hidup. ${ }^{11}$

Proses menuju kesempurnaan terjadi pada awal abad ke-3 M yang berawal dari kawasan sungai Eufrat Irak, yaitu suku Hierah dan Anbar. Pada era ini telah ditemukan bentuk huruf yang lebih sempurna, yaitu menambah beberapa huruf yang tidak terdapat dalam bahasa Semit Utara, yaitu huruf: $t \bar{b} \bar{a}^{\prime}$, dhal, dal, dad, dan ghain. Sedangkan huruf yang sama bentuknya tetapi berlainan pengucapannya, telah dibedakan.

Diperkirakan bahwa seabad sebelum kedatangan Islam, orang Hijaz sudah ada yang mengenal tulisan. Hal ini karena adanya hubungan dagang mereka dengan orang Arabia Utara dan Selatan yang sudah mengenal huruf seperti suku Hunain di Yaman. Mereka melakukan perjalanan sambil belajar baca tulis di Shria, sedang yang lain di Anbar Irak. Meskipun demikian, di Hijaz menurut para ahli sejarah, hanya ada beberapa orang saja yang pandai tulis baca, terdiri dari orang Quraish dan orang Madinah, khususnya orang Yahudi. Di antara mereka ada nama Bishr ibn 'Abd alMalak al-Kindi yang belajar kepada suku Anbar. Ia datang ke Makkah, lalu kawin dengan keluarga Umayah kakek Mu'awiyah dan mengajari tulis baca orang-orang Quraish.

Setelah Islam datang, banyak orang Islam yang pandai baca tulis, terutama para pemuda, seperti 'Ali ibn Abi Táalib, 'Umar ibn Khațab, 'Uthmān ibn 'Affān, Abū Sufyān, Mu'àwiyah ibn Abỉ Sufyān, 'Tbān, 'Uthmān (keduanya putra Sa'id ibn Khālid ibn Khudzaifah), Talhah ibn 'Ubaidillāh, Yazì ibn Abỉ Sufyān, Khāțib ibn 'Amr ibn Khālid ibn 'Abd al-Shams, al-'Alā ibn al-Hazramī, serta Abū Salmah ibn 'Abd al-'Uzzā. ${ }^{12}$

\section{Dobrakan dari al-Qur'ān}

Berbeda dengan bangsa-bangsa lain seperti Mesir Kuno, Babilonia dan Cina, yang seluk-beluk sistem tulisannya bermula ribuan tahun sebelumnya, bangsa Arab dalam hal ini merupakan pendatang yang benar-benar terlambat. Walaupun huruf Arab menempati urutan kedua

\footnotetext{
${ }^{11}$ Ibid., hlm. 8.

${ }^{12}$ Ibid., hlm. 9.
} 
sesudah huruf Latin dalam luas daerah pemakaiannya sampai dewasa ini, namun sebenarnya huruf Arab baru berkembang jauh di kemudian hari.

Keterlambatan perkembangan ini karena bangsa Arab pada umumnya adalah masyarakat pengembara yang tidak begitu memperhatikan bahasa tulis. Mereka bertumpu pada tradisi lisan untuk kepentingan komunikasi dan penyebaran berita. Pada masa sebelum Islam, khususnya pada abad ke-6 M yang merupakan zaman kesusastraan yang penuh semangat kepahlawanan bagi bangsa Arab, puisilah barangkali yang akrab di antara mereka, dan merupakan satu-satunya bentuk pengungkapan sastra. Akan tetapi mereka bertumpu sepenuhnya pada tradisi lisan dalam mengabadikan sajak-sajak mereka. Menurut tradisi sastra Arab, hanya tujuh buah sajak pujian yang bernama al-mu'allaqät ${ }^{13}$ yang dinyatakan sebagai karya agung, ditulis dengan huruf emas dan digantung di dinding Ka'bah. ${ }^{14}$ Bahkan sesudah lahirnya Islam pada awal abad ke-7, al-Qur'an disiarkan pertama kali di kalangan orang Islam tidak melalui tulisan tetapi dengan tradisi lisan.

Sekalipun demikian, sekali mereka menyadari perlunya menyalin bahasa mereka dalam tulisan, maka segera mereka mengungguli bangsa lain di dunia dalam seni menulis indah (kaligrafi). Dalam waktu yang amat singkat mereka menghasilkan seni kaligrafi yang amat mengagumkan, yaitu seni mengalihkan bentuk huruf Arab ke dalam medium seni yang mencerminkan kegeniusan bakat seni mereka yang menakjubkan. Perkembangan ini sangat terkait dengan peran al-Qur'an. Seperti dapat dilihat bahwa wahyu pertama menyinggung perintah "membaca" dan "menulis" (QS. al-'Alaq [96]: 1-5), sebagai ajaran yang mendominasi tempat tertua di antara ajaran-ajaran Islam lainnya. Dapat dipastikan

\footnotetext{
${ }^{13}$ Para periwayat berselisih pendapat tentang nama-nama penyair pemilik al$m i^{\prime}$ allagät. Pendapat paling masyhur menunjuk kepada tokoh-tokoh ini: Imru al-Qais, Tarfah ibn al-'Abd, Zuhair ibn Sulma, Labid, 'Amru ibn Khulsūm, Antarah ibn Shidād dan al-Harith ibn Halzah. Al-Tabrizi menghitung sepuluh personel dengan menambahkan nama-nama Nabighah al-Zibyani, al-A'șa dan 'Abid ibn al-Abrash. Lihat, Aḥmad al-Iskandari dan Mustafa Anani, al-Wasit fí al-Adab al-'Arabi wa Táriblei (Mesir: Dairāt al-Ma'arif, t.t.), hlm. 357.

${ }^{14}$ Yasin Hamid Safadi, Kaligrafi Islam, terj. Abdul Hadi WM Jakarta: PT. Pantja Simpati, 1986), hlm. 7; D. Sirajuddin AR, "Al-Qur'an dan Reformasi Kaligrafi Arab" dalam Ulumul Qur'an No. 3 Vol. I, Th. 1989, hlm. 52.
} 
bahwa qalam atau pena dalam konteks ayat tersebut memiliki kaitan erat dengan seni menulis. Kekuatan magis dari ayat al-Qur'an yang lain dapat ditemukan dalam ayat pertama surat al-Qalam: "Nun, perhatinkanlah qalam dan apa saja yang mereka tulis". ${ }^{15}$

Al-Qur'an sendiri memaparkan secara utuh seperangkat alat tulis. Tinta digambarkan dalam kata midad (QS. al-Kaḥfi [18]: 109) dan nün. Pena dengan qalam, alas untuk menulis dengan laụ atau papan (QS. al-Burūj [85]: 21-22; al-A'rāf [7]: 145), raqq atau kulit halus (QS. al-Thūr [52]: 1-3), suhuf atau lembaran (QS. 'Abasa [80]: 13-14; al-A'là [87]: 18-19) dan qirțas atau kertas (QS. al-An'àm [6]: 6). Ini hanyalah istilah-istilah yang digunakan sesuai dengan masa dan kebutuhannya. Meskipun sekarang telah banyak peralatan yang lebih modern, namun pesan dari ayat di atas tetap tertuju pada obyek yang sama, yakni peralatan tulis dan media komunikasi. Dari sini, para kaligrafer mendapatkan inspirasi untuk mencipta dan berkarya serta mengembangkan mata rantai penghubung antara kaligrafi dan dunia Islam. ${ }^{16}$

Beberapa tahun pesan ayat-ayat ini belum mendapatkan banyak sentuhan. Hanya ada beberapa tokoh yang pandai menulis dan belajar kaligrafi langsung dari Bishr dan Harb, dua moyang pembawa kaligrafi kepada tokoh-tokoh Quraish. Mereka itu adalah 'Umar ibn Khațtab, 'Uthmān ibn 'Affan, 'Ali ibn Abi Tạalib, Talḥ̣ah ibn 'Abdillāh, Abū 'Ubaidah ibn al-Jarrah, dan Mu'awwiyah ibn Abi Sufyān. Awal kebangkitan minat baca tulis di kalangan kaum Muslim muncul setelah Nabi Muhammad SAW dan pengikutnya hijrah ke Madinah. Pada tahun kedua hijriah, meletus perang Badar yang berakhir dengan kemenangan tiga ratus

${ }^{15}$ Kontroversi penafsiran terjadi pada kata nün. Yang lebih akrab dalam pemahaman kita adalah yang berdasar pada riwayat Ibn 'Abbās, yang diikuti oleh al-Dahak, al-Ḥasan dan Qatadah, bahwa arti nün adalah dawat atau tinta. Ini paralel dengan Hadith yang dikeluarkan Abū Hāatim riwayat Abū Hurairah, Nabi mengatakan: "Allah menciptakan nūn, yakni dawat". Riwayat lain yang bersumber dari riwayat Israiliyyat menafsirkan kata nūn in dengan ikan̂ nūn yang menelan Nabi Yữnus. Pengarah penăfsiran ini cukup besar, sehingga Mujāhid, Muqātil, dan al-Suddi menghubungkan dengan kata dhun nün (panggilan Nabi Yùsuf) pada surat al-Anbiyā' ayat 87.

${ }^{16}$ Keanehan yang mungkin boleh diajukan adalah tentang Nabi Muhammad SAW yang ummi (QS. al-A'raf [7]: 157-158), tetapi fatwa pertama kepada umatnya adalah agar umatnya tidak boleh menjadi orang bodoh, dengan belajar membaca dan menulis. 
pasukan Islam atas seribu lebih tentara kafir Makkah. Kemenangan ini merupakan detik-detik menentukan bagi kelangsungan Islam selanjutnya. Lebih dari itu, kemenangan tersebut juga memberi arti yang sangat signifikan terhadap perkembangan seni baca tulis, yang dapat di lihat pada kebijaksanaan Rasul dalam memberikan sanksi terhadap tawanan perang. Bagi tawanan yang enggan masuk Islam dapat dibebaskan dengan tebusan. Sedangkan bagi mereka yang miskin dan enggan masuk Islam tetapi pandai baca tulis, diberi kewajiban mengajari tulis baca kepada sepuluh pemuda Madinah. ${ }^{17}$

Hal ini merupakan perhitungan yang sangat tepat, sekaligus sebagai kiat dari sebuah gerakan radikal untuk membasmi buta huruf. Dalam waktu relatif singkat, pengetahuan baca tulis menyebar di kalangan kaum Muslim. Sebab, setiap pemuda yang mendapat ilmu baru ini, diwajibkan pula menyebarkannya kepada teman-teman dan saudaranya. Pada saat wahyu penghabisan turun, Rasul telah memiliki lebih dari 40 orang kaligrafer ahli. Empat orang di antaranya merupakan juru tulis Rasul paling utama yang kelak menulis muṣhaf 'Uthmāni, yaitu: Zaid ibn Thābit, 'Abdullāh ibn Zubair, Sa'id ibn al-'Aṣ, dan 'Abdurraḥmān ibn alHāarith ibn Hishām. ${ }^{18}$

Dalam perkembangan selanjutnya, selain menemukan kebebasan, juga tidak terdapat hambatan teologis yang mengacu pada kata haram, sebagaimana yang dikenakan pada seni lain, seperti seni lukis, tari dan suara, yang dicap Nabi sebagai malabi. Bahkan secara impresif Nabi mengatakan: "Tulisan yang bagus akan membuat kebenaran tampak nyata." "Barangsiapa meraut pena untuk menulis ilmu maka Allah akan memberinya pohon di surga yang lebih baik dari pada dunia dan isinya." "Dan barangsiapa menulis Bismillabirrahmāanirrạ̣im dengan khaṭ yang

17Informasi tentang hal ini, bisa dilihat dalam Hamka, "Pasal Ghanimah", Tafsir Al-Az̧har Juz X (Jakarta: Pustaka Panjimas, tt).

${ }^{18}$ Tentang empat tokoh kaligrafer utama ini lihat, al-Iskandari dan Muștafa Anani, al-Wasit fí al-Adab, hlm. 123. 
indah, ia berhak masuk surga tanpa hisab." "Hendaknya kalian mempercantik tulisan, karena dia itu adalah kunci-kunci rezki". ${ }^{19}$

Pernyataan-pernyataan yang sangat impresif dari kalangan ulama, cendekiawan dan penguasa, semakin mengukuhkan keberadaan para kaligrafer. Ja'far misalnya mengatakan: "Tinta itu merupakan sebagian dari peradaban yang baik." Seorang ahli hikmah mengatakan: "Gambaran tinta di depan mata hitam pekat, di depan hati putih bagai salju." "Bintang-bintang kebijaksanaan tampak dalam gelapnya tinta."20

Pendorong perkembangan kaligrafi yang kedua adalah adanya beberapa Hadith yang secara tekstual "mengancam" para pembuat gambar (tasūir) dan sikap fuqahä' yang memberi tanggapan reaktif terhadap "ulah" seniman lukis dan pematung. ${ }^{21}$ Oleh karena itu, para seniman Muslim angkatan pertama bersikap menghindar dari kemungkinan menuangkan ide-idenya dalam gambar, apalagi dalam bentuk patung yang bernyawa. Muhammad 'Abd al-Jabbār Beg dalam Fine Art in Islamic Civilization seperti dikutip D. Sirajuddin AR menyinggung data yang ironis tentang bidang seni rupa yang menimbulkan salah paham di kalangan masyarakat Muslim, yakni meskipun para teolog Muslim tidak pernah dikenal sebagai ahli seni, namun mereka termasuk kritikus seni rupa yang paling ribut dalam masyarakat Muslim. Dalam perkembangannya, para seniman Muslim itu kemudian melaksanakan kreasinya tanpa rasa takut, dan memandang pendapat fuqahä' tersebut lemah. Secara arkeologis, seperti ditunjukkan oleh Taymur Pasha dalam al-Tașīir Inda al-'Arab, kaum Muslim kemudian menggunakan gambar dan lukisan untuk

${ }^{19}$ Ḥadith-hadith ini perlu dianalisis secara kritis dengan metode takbrij al- hadith mengingat redaksi matn-nya terkesan terlalu tendensius dan tidak rasional dalam membela eksistensi dunia kaligrafi.

${ }^{20}$ Lihat, Sirajuddin AR., "Al-Qur'ān dan Reformasi", hlm. 57.

${ }^{21}$ Larangan atas bentuk karya cipta yang bersifat figuratif, seperti patung atau seni pahat yan̈g berbentuk mănusia, binatang atau bendă-benda mati, mënurü Nasr karena dalam pemikiran Islami tidak membolehkan adanya reduksi dari atas ke bawah, yang intelektual ke tingkat korporeal, atau yang suci ke tingkat yang duniawi. Lihat, Seyyed Hossein Nasr, Spiritualitas dan Seni Islam, terj. Drs. Sutejo (Bandung: Mizan, 1993), hlm. 15. Lebih dari itu, semuanya memang dimaksudkan untuk menghindari munculnya bentuk persembahan kepada selain Allah. 
menghiasi karpet, gelas, piala, tunggul, bendera, benda-benda dari kayu, batu, kaca, gading, tembaga, proselin, plaster dan media lainnya. ${ }^{22}$

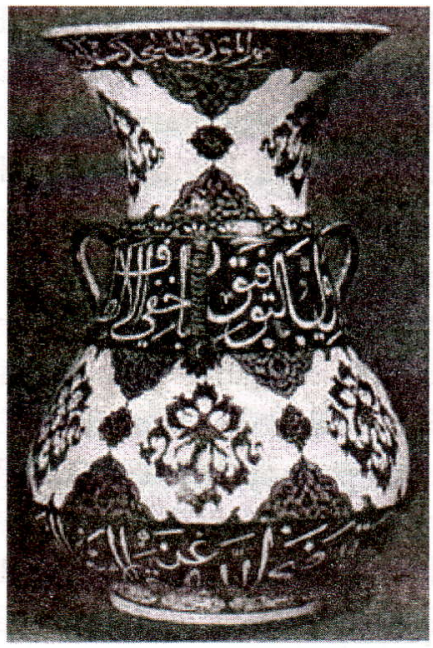

Gambar 1: Lampu masjid dari keramik dengan inskripsi tulisan thuluth dari Turki tabun $1549 \mathrm{M}$.

Kasus ini menguntungkan dunia seni tulis kaligrafi. Rasa takut menggambar makhluk bernyawa, menempatkan seni lukis pada posisi tertekan, dan tidak mendapatkan publikasi menyolok yang melebihi seni menulis indah. Akhirnya kaligrafi dijadikan pelabuhan tempat menumpahkan keresahan seni dan mencurahkan kerinduan estetika umat Islam serta para seniman Muslim. Meskipun demikian, secara terselubung ternyata seni kaligrafi tidak bisa mengelak secara total dari keterlibatannya dalam gambar-gambar figuratif tersebut. Hal ini dapat dilihat dalam seni figurasi yang materi goresannya berasal sepenuhnya dari tulisan Arab. Misalnya, do`a Syiah dalam tulisan thuluth berbentuk seekor elang oleh Muhammad Fațiyab dari Persia pada abad 19; tulisan Tauq'i dari Persia

${ }^{22}$ Sirajuddin AR, "Al-Qur’an dan Reformasi", hlm. 53; Ahmad Fikri, "Arsitektur dan Benda-Benda Seni" dalam Komisi Nasional Mesir untuk UNESCO Sumbangan Islam kepada Ilmu dan Kebudayaan, terj. Muhammad Tafsir (Bandung: Pustaka, 1986), hlm. 332. 
pada abad 19 yang berisi doa kepada 'Ali: 'ATi ibn Abi Țalib, radiyallabu ta'áa 'anbu wa karrama wajbabu, serta doa Syiah dalam bentuk tulisan Naskhi yang disusun dalam bentuk seekor kuda oleh Sayyid Husain 'Ali dari Persia, tahun $1848 .^{23}$

Al-Qur'an kemudian menjadi sumber segala inspirasi dan dijadikan ajang perburuan kreasi yang tak ada habis-habisnya. Lebih dari seratus tahun sebelum Islam, perjalanan kaligrafi Arab sangat tersendat dan tidak melahirkan keanekaragaman. Tetapi hanya beberapa puluh tahun sesudah kedatangan Islam, terjadi lompatan besar hingga akar-akar tulisan pecah menjadi 400 aliran. Sikap ulama terhadap kaligrafi yang bertolak belakang dengan sikap mereka terhadap seni gambar makhluk bernyawa, di samping sambutan pundi-pundi dinar para Sultan atas karya kaligrafer yang berkualitas, telah melahirkan banyak maestro sekaligus menempatkan kaligrafi ke puncak seni. Kecenderungan inilah yang kemudian melahirkan klaim dengan lebih dikenalnya istilah "Kaligrafi Islam" ketimbang "Kaligrafi Arab". ${ }^{24}$

\section{Kaligrafi sebagai Seni}

Sebagai bagian dari ekspresi jiwa seni, kaligrafi Islam berkembang mengikuti kekuatan imajinasi para kaligrafer di setiap zaman. Dalam perkembangan awal, setelah Islam datang dengan semangat revolusionernya, dinamika kaligrafi terkait dengan pendokumentasian wahyu Tuhan. Sebagai sumber nilai, di samping dihafal, Nabi juga menganjurkan pendokumentasian al-Qur'an dalam bentuk tulisan. Penulisan wahyu ini semakin disadari signifikansinya ketika terjadi pertempuran Yamamah. Banyaknya para huffaz yang gugur, dikawatirkan bisa menjadi penyebab lenyapnya al-Qur'an.

\footnotetext{
${ }^{23}$ Untuk contoh-contoh ini, lihat Safadi, Kaligrafi Islam, hlm. 138-139; Sirajuddin AR, Seni Kaligrafi, hlm. 155.

${ }^{24}$ Selama ini terjadi kerancuan pemahaman antara "Arab" dan "Islam". Seringkali sebutan "Arab" diidentikkan dengan "Islam", meskipun Islam di sini belum jelas ukurannya. Sehingga menurut M. Arkoun, penulisan Islam untuk menisbabi sesuatu, harus ditulis dengan tanda petik. Lihat, Machasin, "Kaligrafi sebagai Simbol Budaya Islami" Makalah Diskusi Panel Kaligrafi Islami Nasional (Yogyakarta: Panitia MTQ XVI, 1991), hlm. 4.
} 
Meluasnya wilayah Islam dengan berbagai konsekuensinya, seperti para pemeluk Islam yang berasal dari suku dan dialek yang beragam, juga menyebabkan kaligrafi berkembang secara dinamis, karena saat itu kaligrafi menjadi medium penting untuk mengabadikan wahyu Tuhan sebagai pedoman umat Islam. Tulisan Arab yang semula tanpa tanda baca atau titik yang membedakan antara satu huruf dengan huruf lain, mulai disempurnakan, seperti yang dilakukan oleh Abū al-Aswad al-Duāli (w. 69 H/688 M) dan al-Khafil ibn Ahmad (w. 170 H/786 M). ${ }^{25}$

Setelah gerakan penyempurnaan yang lebih bersifat praktis di atas, kaligrafi menuju dunia baru, yaitu dunia seni. Perkembangan ini terjadi selama enam periode, sebagaimana dicatat oleh Habibullāh dalam Atlas al-Khat wa al-Khututat. ${ }^{20}$ Pertama, periode penyempurnaan tanda baca yang dilakukan oleh $\hat{A} \dot{b u}$ al-Aswad al-Duali, sebagaimana dijelaskan di atas. Kedua, periode modifikasi dan pembentukan gaya-gaya, pengelokan dan penghimpunan mazhab-mazhab yang dimulai sejak akhir kekhalifahan Bani Umayah dan awal Bani Abbasiyah hingga kekuasaan Al-Ma'mūn. Pada periode ini lahir 24 gaya khat. Ketiga, periode penyempurnaan anatomi huruf oleh Ibn Muqlah (w. 328 H). Ia mengkodifikasi kaligrafi berstandar kepada 14 aliran yang dipilih, kemudian menentukan 12 kaidah untuk jadi pegangan seluruh aliran. Keempat, periode pengembangan pola-pola khat sebagaimana yang dikodifikasi Ibn Muqlah. Tugas ini dipelopori oleh Ibn Bawāb (w. $413 \mathrm{H}$ ) yang menambahkan unsur-unsur zukbrufab (penghias) pada 13 gaya khaṭ yang menjadi elemen eksperimennya. Kelima,

${ }^{25}$ Menurut sumber-sumber terpercaya, 'Ali ibn Abi Tàlib yang mengintruksikan Abū al-Aswad ad-Du'ali untuk merumuskan tanda baca pada tulisan. Sasaran pertamanya adalah al-Qur'an, karena di sini ada kekawatiran terjadinya salah baca. Ada riwayat lain yang menyebut perumusan tanda baca yang dikerjakan Abū al-Aswad tersebut terjadi pada permulaan daulat Umayah masa kekuasaan Mu'awiyah. Ziyād ibn Abih, pembantu terdekat Mu`awiyah konon meminta kepada Abu al-Aswad untuk menciptakan shakal guna membuktikan adanya huruf hidup. Kemudian usaha ini diteruskan oleh al-Khalil ibn Ahmad al-Farahidi (w.170 H/786 M), dengan menggunakan titik untuk membedakan huruf yang bentuknya sama, tetapi ejaannya berbeda. Kreasi Khalil inilah yang kemudian menjadi dasar untuk tanda-tanda dalam tulisan Arab sampai sekarang. Lihat, Husain, Seni Kaligrafi, hlm. 15-16; Sirajuddin AR, Seni Kaligrafi, hlm. 65-67.

${ }^{26}$ Lihat, D. Sirajuddin AR, "Memahami "Lompatan" Aziz" dalam Abd 'Aziz Ahmad, Ragam Karakter Kaligrafi Islam (Jakarta: Bumi Aksara, 1996), hlm. vi. 
merupakan periode pembedaan dan pengolahan gaya-gaya serta penetapan al-aqTam al-sittab (Thuluth, Naskhi, Raihāni, Muhaqqaq, Tauqi dan Riq'ah) yang ditemukan pada periode kedua sebagai masterpiece. Tugas ini dipandu oleh Yāqut al-Musta'simi (w. $698 \mathrm{H}$ ), yang mengembalikan hukum-hukum Ibn Muqlah dan Ibn Bawāb pada asas geometri dan titik yang populer di zamannya, sambil memperhalus gaya-gaya yang sedang berkembang. Keenam, periode munculnya tiga gaya baru khat yaitu Ta'liq, Nasta'liq dan Sikasteh dari tangan kaligrafer Iran. Angkatan ini dimulai pada abad 6 dan $7 \mathrm{H}$, dan masuk dalam periode pematangan aliran-aliran pada abad 8 dan $9 \mathrm{H}$. Kelahiran tiga gaya baru ini tidak menghentikan proses perkembangan, tetapi justru merupakan titik pijakan ditemukannya olahan-olahan baru yang menunjukkan dinamika yang sangat pesat.

Dari kategorisasi di atas, terlihat bahwa perkembangan kaligrafi, sebagai sebuah tulisan, tidak lagi sekadar menjadi medium penjelas ide-ide dalam berkomunikasi. Lebih dari itu, karakteristik seni menjadi bagian penting dari sebuah ekspresi komunikasi artistik. Oleh karena itu, dalam beberapa segi, keindahan kaligrafi seringkali justru menjadi "problem" tersendiri bagi sebagian orang. Misalnya, bentuk khat Naskhi dan Thuluth secara tekstual lebih memudahkan orang dalam menangkap makna tekstual yang disampaikan dibanding khạ Diwāni dan Diwāni Jāli yang cenderung rumit dan kompleks detail lekukan goresan huruf-hurufnya.

Dari sinilah muncul makna spesifik dan kepuasan tersendiri dalam konteks seni yang mulai direpresentasikan oleh para kaligrafer selanjutnya. Mereka terus-menerus melakukan pencarian, yang kadang terkesan "memaksa" berbagai bentuk huruf yang selama ini telah baku. Apa yang dilakukan oleh Najā al-Mahdani dari Tunisia menjadi salah satu bukti dalam kecenderungan ini. Al-Mahdani, lewat kreasinya, oleh Charbal Dagir dianggap telah melakukan pemaksaan terhadap huruf-huruf yang telah berkaidah dengan permainan gila (al-la'bah al-majnünab). ${ }^{27}$ Fakta ini menunjukkan bahwa ekspresi yang bebas dalam menampilkan bentuk-bentuk kreasi, telah menempatkan kaligrafi dalam wacana artistik yang unik dan spektakuler. Kegelisahan-kegelisahan rasa seni telah mewujud dalam berbagai bentuk goresan dan lekukan huruf yang lincah

${ }^{27}$ Mengenai "kegilaan" al-Mahdani ini, lihat ibid., hlm. vii. 
dan bebas yang menyimpan daya magis tersendiri. Yāqut al-Musta'șimi (w. 698 H/1298 M), kaligrafer kenamaan pada masa kesultanan Turki 'Uthmāni (Ottoman), sampai-sampai mengibaratkan kaligrafi sebagai arsitektur ruhani yang diekspresikan lewat medium jasmani (al-khatțu bandasah ruḅaniziah zahäăt bi älah al-jismiyyah). M. Ugur Derman dalam Jurnal Arts and The Islamic World menyebutnya sebagai suatu ilmu ukur spiritual yang menghasilkan perabot kebendaan (Calligraphy is a spiritual geometry brought about with material tools). ${ }^{28}$ Kaligrafi menjadi lisan al-yadd, untuk mengungkapkan pelbagai citra dan rasa keindahan serta keagungan spiritual. Oleh karena itu, seperti dikatakan Wang Hsichih (w. 379) bahwa keindahan seni kaligrafi bisa lembut sebagai awan yang berarak-arakan dan bisa perkasa sebagai naga yang sedang marah. ${ }^{29}$

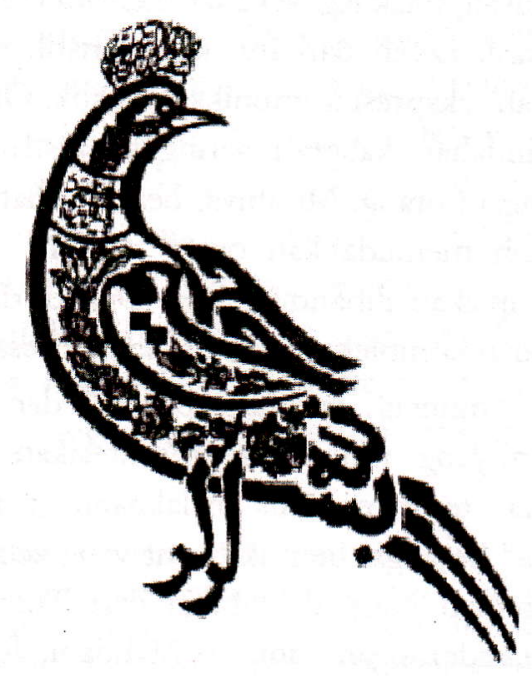

Gambar 2: Tulisan Basmalab berbentuk burung dengan khat thuluth

${ }^{28}$ Untuk informasi ini lihat, Sirajuddin AR, "Al-Qur'an dan Reformasi", hlm. 54; Sirajuddin AR, Seni Kaligrafi, hlm. 3.

${ }^{29}$ Lihat, Suwarsono dalam Pameran Kaligrafi Islam Indonesia pada Muktamar Media Massa Islam Sedunia I, Jakarta 1-3 September 1980. 
Dalam konteks Indonesia pada periode awal Islam masuk, sebenarnya kaligrafi belum begitu berkembang dan menonjol sebagai karya seni rupa jika dibandingkan dengan negara-negara lain. Hal ini karena penerapan kaligrafi Islam sebagai hiasan masih sangat terbatas. Bangunanbangunan tertua pada zaman permulaan kerajaan Islam, tidak memberi peluang yang berarti bagi penerapan hiasan kaligrafi Islam. Masjid-masjid lama, seperti di Banten, Cirebon, Demak dan Kudus menerapkan kaligrafi hanya sebagai pelengkap motif hias yang bersumber pada tradisi seni hias Indonesia-Hindu. Ini disebabkan karena konstruksi bangunan masjidmasjid lama di Indonesia didominasi kayu yang tidak memberi peluang besar hadirnya hiasan kaligrafi Islam yang kaya. Selama masa-masa itu hanya ditemukan sebatas pada hiasan mimbar masjid, pada batu nisan dan terkadang disatukan dengan aksara Jawa dalam bentuk candra sengkala yang hanya berfungsi sebagai tanda peringatan berdirinya masjid, seperti yang terdapat pada masjid Mantingan, masjid Sumenep, Sendang Duwur dan masjid Keraton Yogyakarta. ${ }^{30}$

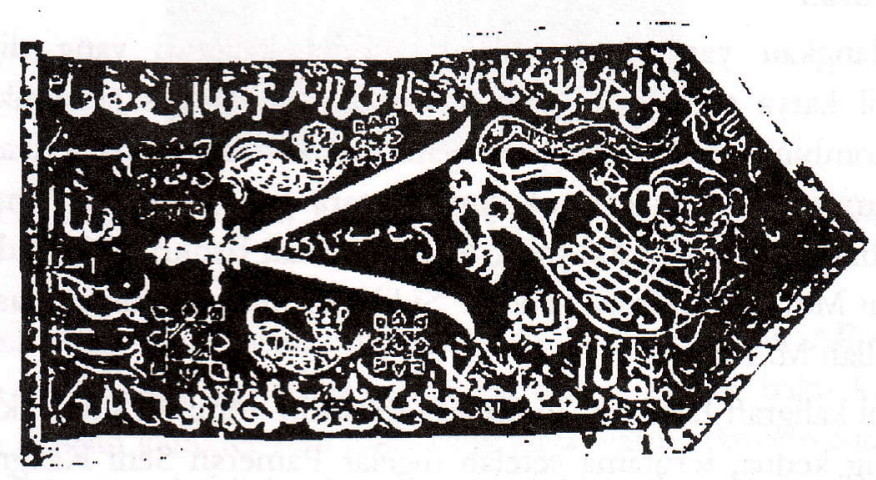

\section{Gambar 3: Motif kaligrafi Arab dan motif perlambangan pada kain batik untuk panji}

Alam pikiran kosmis-magis di Jawa yang terus berpengaruh hingga zaman Islam, juga mempengaruhi tampilan kaligrafi Islam. Seni kaligrafi Islam di Indonesia saat itu tidak ditujukan untuk mengembangkan nilai keindahan tulisan Arab sebagai karya seni tulis, tetapi lebih sebagai tanda

${ }^{30}$ Wiyoso Yudoseputro, Pengantar Seni Rupa Islam di Indonesia (Bandung: Angkasa, 1986), hlm. 116-117. 
perlambang yang sudah mempunyai bidang dan motif lukisan, seperti dalam bentuk tokoh-tokoh yang ada dalam pewayangan atau bentukbentuk makhluk hidup. Fungsi dekoratifnya hanya dapat ditemukan pada beberapa obyek yang mengandung unsur magis, seperti keris, tombak, pedang, perisai, dan baju.

Kegairahan kaligrafi Islam sebagai seni mulai bangkit pada era 1970an. Kegairahan ini menurut D. Siradjuddin AR, kemudian memunculkan dua aliran besar dalam kaligrafi di Indonesia, yakni: (1) kaligrafi murni dan (2) lukisan kaligrafi. ${ }^{31}$ Yang pertama dimaksudkan sebagai kaligrafi yang mengikuti pola-pola kaidah yang sudah ditentukan dengan ketat, yakni bentuk yang tetap berpegang pada rumus-rumus dasar kaligrafi yang baku. Di sini dapat dibedakan dengan jelas aliran-aliran seperti Naskhi, Thuluth, Raihāani, Diwāni, Diwāni Jāi, Ta’liq, Färisi, Küfi, dan Riq’ah. Penyimpangan maupun pencampuradukan satu dengan lainnya dipandang sebagai suatu "kesalahan". Tokoh-tokohnya dapat kita lihat misalnya, Darami Yunus, Hardyono, Azhari Noer, M. Abdur Razzak Muhili, dan Amir Hamzah.

Sedangkan yang kedua adalah model kaligrafi yang digoreskan pada hasil karya seni lukis, atau kaligrafi yang dilukis sedemikian rupa dengan kombinasi warna yang beragam, bebas dan tanpa terikat dengan rumus-rumus baku. Tokoh-tokohnya antara lain, Affandi, Amri Yahya, Abas Alibasyah, Amang Rahman, Saiful Adnan, Bachri Makhfudz, Batara Lubis, But Mukhtar, Damas, Fadjar Sidik, Motinggo Busye, Hasanuddin, dan Saifullah M. Aziz.

Seni kaligrafi Islam di Indonesia semakin tumbuh subur, khususnya aliran yang kedua, terutama setelah digelar Pameran Seni Kaligrafi Islam pada MTQ-XI di Semarang dan pameran pada Muktamar Media Massa Islam Sedunia I di Jakarta 1-3 September 1980. Tokoh-tokoh aliran yang kedua di atas, adalah para pelukis tulen yang hanya mencoba mengguratkan kaligrafi Islam dalam lukisannya, jadi mereka bukan kaligrafer. Dari tangan mereka ini muncul berbagai bentuk gaya yang beragam. Seperti Amri Yahya, gaya tulisannya mirip berbentuk Naskhi, tetapi memanjang dan tidak banyak lekukan yang menyudut seperti dalam karakter Fārisi,

${ }^{31}$ Sirajuddin AR, Seni Kaligrafi, hlm. 9. 
dengan menggunakan medium kain batik. Saiful Adnan memiliki gaya tulisan yang mirip khat Naskhi, namun semua bentuk huruf diakhiri dengan bentuk-bentuk runcing yang mengecil dan memanjang, sehingga karakter bentuk Naskhi tidak lagi dominan.

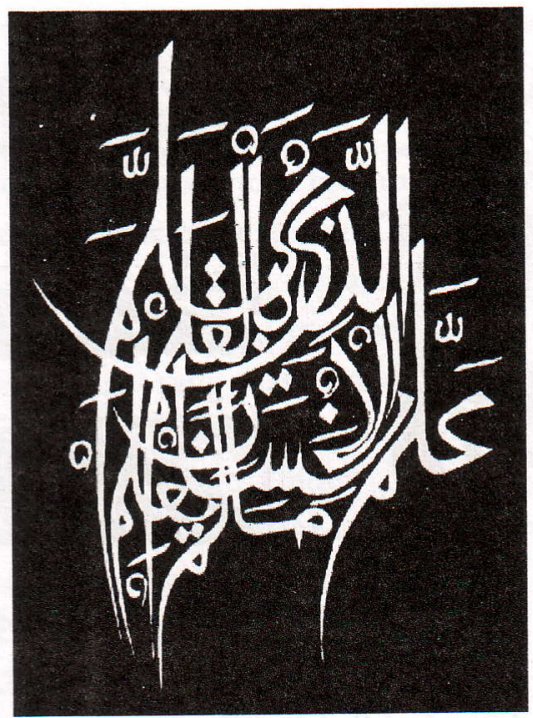

Gambar 4: Lukisan Saiful Adnan, desain sampul Pameran Kaligrafi Islam Indonesia 1983, MTQ XIII, Padang.

Selain dua aliran yang dikategorikan D. Siradjuddin AR di atas, masih ada satu aliran lagi yang taat pada rumus-rumus baku kemudian dipadukan dengan karakter seni lukis yang kaya warna. Bahkan back groundnya seringkali sengaja diciptakan sang pelukis sebagai simbol-simbol keindahan yang lain selain tulisan, yang kadangkala menjadi tafsir makna dari kandungan tulisan. Bentuk ini sering dipakai oleh D. Sirajuddin AR dalam berbagai karyanya.

Di era 90-an, Abdul Aziz Ahmad, alumni Jurusan Seni Murni Fakultas Seni Rupa dan Desain ISI Yogyakarta dan pengajar tamu pada Lembaga Kaligrafi Jakarta, menyusun karakter-karakter huruf Arab yang berbeda dengan rumus-rumus baku yang selama ini dikenal. Ada sembilan karakter yang ia ciptakan, yaitu: karakter api dengan nuansa ekspresi 
seperti kobaran api, karakter air dengan kesejukan dan kelembutan yang terdapat dalam sifat air, karakter tajam, karakter gemuk, karakter kurus, karakter tali, karakter bambu, karakter lipatan dan karakter balok. Semua karakter ini mengambil sifat yang ada dalam nama-nama karakter tersebut. $^{32}$
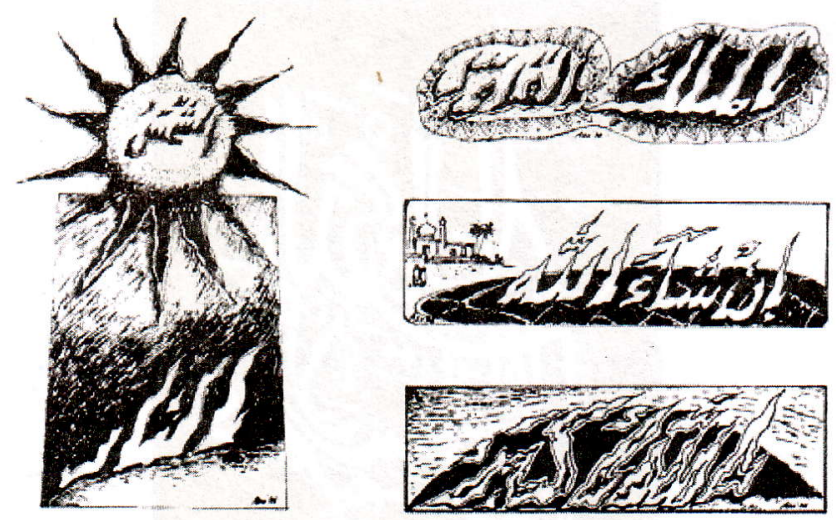

Gambar 5: Contoh karakter api yang dibuat oleh Abdul Aziz Abmad

\section{E. Kaligrafi sebagai Simbol Spiritual}

Dalam dunia Islam, kaligrafi tidak saja sebagai sebuah ekspresi seni, tetapi bentuk-bentuk dan irama geometri matematik yang digoreskannya yang berawal dari berbagai titik, telah menjadi suatu ekspresi dari simbolsimbol spiritual yang cukup menggetarkan jiwa. Setiap huruf mempunyai kepribadian tersendiri untuk melambangkan bentuk visual Tuhan dan sifatNya, ataupun melambangkan gerak-gerak hati kehambaan. Setiap karakter dari semua huruf menjadi tafsir atas kesadaran spiritual.

Secara umum bentuk-bentuk huruf kaligrafi Islam mempunyai dua karakter, yaitu: vertikal dan horisontal. Bentuk tegak alif yang kukuh misalnya, merupakan ekspresi simbolik dari pengakuan sang kaligrafer akan adanya Zat yang Maha Tinggi. Alif dengan vertikalitasnya melambangkan Tuhan Yang Maha Kuasa dan Prinsip Transenden yang dariNya segala

${ }^{32}$ Untuk detail-detail dari sembilan karakter tersebut, baca Ahmad, Ragam Karakter. 
sesuatu berasal. Pada nama Allah dalam tulisan Arab, kita melihat dengan jelas suatu garis horisontal, yakni gerak penulisnya, kemudian garis tegak lurus dari alif dan lam dan semacam garis melingkar yang secara simbolik dapat disamakan dengan suatu lingkaran. Tiga unsur ini menurut Nasr, seperti menunjukkan tiga dimensi yaitu: ketenangan yang "horisontal" dan tak ubahnya seperti gurun atau lapisan salju; kekuasaan yang "vertikal" bagai kekokohan gunung; dan misteri yang memanjang "ke dalam" serta berhubungan dengan Zat Allāh. ${ }^{33}$

Sedangkan gerakan horisontal merupakan gerakan kesetiaan pada prinsip kepenulisan dan kesesuaian serta keharmonisan antara goresan satu dengan goresan yang lain. Ini adalah simbol dari suatu masyarakat yang mampu bekerja sama untuk mencapai tujuan bersama, sehingga terbentuk pluralitas hidup yang harmonis. Bila dalam kaligrafi prinsip keseimbangan, kesamaan dan keharmonisan bentuk menjadi ciri keprimordialannya, maka dalam hidup masyarakat terdapat prinsip keadilan, kebebasan dan keamanan atas hak-hak individu yang dilestarikan agar kehidupan bersama berjalan terus dengan baik. Bila kemajuan masyarakat sangat tergantung pada kebersamaan anggotanya, maka keindahan kaligrafi Islam menjadi nyata dalam keharmonisan dan keterpaduan hurufnya.

Oleh para sufi, tidak hanya huruf alif saja yang memberikan makna-makna simbolik dari gerak spiritual, tetapi keseluruhan huruf-huruf al-Qur'an menjadi cerminannya. Huruf $b a^{\prime}$ misalnya, garis mendatarnya dianggap sebagai lambang daya penerimaan prinsip maternal dan pasif serta dimensi keindahan yang menyempurnakan keagungan. Huruf wawn sesuai dengan hubungan antara alam makhluk dengan Ketunggalan Ilahi. ${ }^{34}$ Evolusi bermacam-macam bentuk alam makhluk dari Ketunggalan, kadang-kadang dilukiskan oleh pemunculan berbagai huruf dari huruf alif. Fariduddin Attar melukiskan pemunculan huruf-huruf itu sebagai berikut:

"Ketika alif membongkok terjadilah huruf dal, ketika lengkoknya berubah sedikit lahirlah $r a^{\prime}$, sesaat kedua ujung alif melengkung ke

${ }^{33}$ Nasr, Spiritualitas dan Seni, hlm. 45.

${ }^{34}$ Ibid., hlm. 46. 
atas muncullah $b a^{\prime}$, dan setelah alif membengkok seperti ladam kuda terciptalah $\overline{n u} n . " 35$

Huruf $\bar{n} \bar{n}$ karakternya menyerupai sebuah tempat tinta yang berisi tinta yang dengannya pola-pola dasar segala sesuatu dituliskan di al-laukh al -mabf $\bar{u} z$. Huruf $\overline{n u} n$ ini juga menyerupai sebuah kapal yang mengangkut kemungkinan-kemungkinan suatu perputaran dari pengejawantahan di atas lautan ketiadaan. Kamāluddin Husayn al-Käshifi, sufi Persia abad ke-9 H dalam tafsir Qur'annya Mawäibib al'ÁAliyab seperti dikutip Nasr menghubungkan huruf $\overline{n u}$ dengan huruf pertama dari cahaya (nür) yang merupakan realitas pertama yang diciptakan oleh Tuhan, dan huruf terakhir dari ar-Raḥmän, Tuhan Yang Maha Pengasih yang mendasari timbulnya seluruh makhluk. ${ }^{36}$ Ibn 'Arabi mengajukan daftar semua (dua puluh delapan) huruf abjad Arab, yang masing-masing sesuai dengan salah satu nama Ilahi. ${ }^{37}$

Dalam buku al-Kahf wa al-Raq̄im fi Sharḅ Bismillah al-Raḅmān al-Raḥim, sufi terkemuka abad ke-8 $\mathrm{H}$, 'Abd al-Karim al-jili menyebutkan bahwa titik merupakan substansi yang tidak dapat dibagi (al-jawhar al-basiti), sedangkan huruf-huruf adalah tersusun (aljism al-murakkab). Titik melambangkan dan merujuk ke Esensi Tuhan. Oleh karena itu ketika ditambahkan huruf apa pun, titik tidak mempunyai bunyi dirinya sehingga penampakan Esensi itu tampak di setiap makhluk sesuai dengan kemungkinaan kesempurnaan makhluk. Dalam kasus ini, Al-jili memaparkan sebuah dialog metaforis antara titik dengan $b a$ ':

"Wahai huruf, Akulah Prinsip-mu...."

"Wahai Tuan, jelaslah bagiku bahwa engkau adalah prinsip-ku," jawab ba'.

$\mathrm{Ba}^{\prime}$ juga menanyakan bagaimana bisa demikian. Titik menjawab bahwa semua huruf dan kata itu sesungguhnya merupakan suatu bentuk yang berasal dari titik. Semua misteri Keesaan Tuhan dilukiskan oleh Al-jili melalui simbolisme dialog antara titik dan $b a{ }^{38}$

${ }^{35}$ Lihat, V.I. Braginsky, Tasanuf dan Sastera Melayu, Kajian dan Teks-Teks (Jakarta: Pusat Pembinaan dan Pengembangan Bahasa dan Universitas Leiden, 1993), hlm. 8.

${ }^{36}$ Ibid., hlm. 35; Annemarie Schimmel, Dimensi Mistik dalam Islam, terj. Sapardi Djoko Damono dkk (Jakarta: Pustaka Firdaus, 1986), hlm. 427-430.

${ }^{37}$ Lihat, Braginsky, Tasawuf dan Sastera, hlm. 8.

${ }^{38}$ Sebagaimana dikutip Nast, lihat Nast, Spiritualitas dan Seni, hlm. 46. 
Tidak hanya karakter huruf-huruf Arab yang dilibatkan para sufi sebagai bentuk simbolik dari kesaksikan spiritualnya. Bahkan peralatan untuk menggoreskannya pun menjadi sarana pengungkapan simbol yang cukup efektif. Pena yang awalnya terbuat dari bambu misalnya, tidak hanya menghasilkan baris-baris dan bentuk kaligrafi yang indah, namun juga melahirkan alunan musik suci dari pecinta Tuhan yang memanggil mereka untuk kembali ke Sumbernya di haribaan Tuhan. Itulah bambu yang disinggung Jalāluddin Rümi dalam syair abadi yang membuka karyanya, Mathnawi:

Dengarkanlab rintiban Bambu nan pilu ini,

yang senantiasa mendesab,

semenjak direnggut dari rumpunnya nan penuh rerumputan,

sebuah alunan rasa nyeri

dan cinta nan membara. ${ }^{39}$

Nyanyian seruling bambu ini menurut Nast adalah imbangan antara sifat musikal huruf-huruf dan kata-kata kaligrafer. Keduanya dihasilkan oleh bambu dan pendengaran manusia untuk kembali ke tempat tinggal spiritualnya melalui peringatan akan pola-pola dasar yang dilukiskan oleh musik dan kaligrafi tradisional dalam bentuk-bentuk suara dan fisual. Dari sisi lain dapat juga dikatakan bahwa bambu yang dipergunakan sebagai alat kaligrafi melambangkan gerak kosmogonis, busur penerusan dari kosmologi tradisional, dan bambu sebagai seruling merupakan gerak kembali ke Asal, busur pendakian. ${ }^{40}$

\section{F. Penutup}

Para sufi selama berabad-abad telah mengambil khazanah hikmah Islam untuk menguak sifat spiritual kaligrafi al-Qur'ān sebagai seni suci dan peranannya dalam kehidupan spiritual. Di antara mereka ada yang membicarakan simbolisme huruf-huruf dan kata-kata, membicarakan secara rinci bentuk-bentuk huruf, dan yang lain menguraikan secara rinci pokok ajaran kesatuan wujud (wiḩdah al-wrijud) melalui simbolisme tinta dan pena. Di sini jelas bahwa pesona keindahan kaligrafi tidak saja menyentuh

\footnotetext{
${ }^{39}$ Tentang syair ini lihat, Reynold A Nicholson, Jalaluddin Rumi Ajaran dan Pengalaman Sufi, terj. Sutejo (Jakarta: Pustaka Firdaus, 1996), hlm. 5.

${ }^{40} \mathrm{Ibid}$., hlm. 48.
} 
Islah Gusmian

ruang arstistik seni dengan segala dinamika dan ragam citra keindahannya, tetapi juga telah bergelut sangat dalam dan intens dengan doktrin esoterisme sufistik yang telah berkembang dalam sejarah Islam yang panjang. 


\section{DAFTAR PUSTAKA}

Ahmad, Abdul Aziz. Ragam Karakter Kaligrafi Islam, Jakarta: Bumi Aksara, 1996.

Al-Iskandari, Ahmad dan Muștafa Anani, al-Wasiț fi al-Adab al-Arabi wa Tarikbit. Mesir: Dar al-Ma'arif, t.th.

Al-Zanzani, Abu Abdullah, Wawasan Baru Tarikh al-Quran. terj. Kamaluddin Marzuki Anwar dan A. Qurtubi Hasan, Bandung: Mizan, 1993.

AR. Sirajuddin D., "Al-Qur'ān dan Reformasi Kaligrafi Arab" dalam Ulumul Qur'an No. 3 Vol. I, Th. 1989.

, Seni Kaligrafi Islam, Jakarta: Pustaka Panjimas, 1985.

, "Memahami "Lompatan" Aziz" dalam Abdul Aziz Ahmad, Ragam Karakter Kaligrafi Islam, Jakarta: Bumi Aksara, 1996.

Braginsky, V.I., Tasawuf dan Sastera Melayu, Kajian dan Teks-teks, Jakarta: Pusat Pembinaan dan Pengembangan Bahasa dan Universitas Leiden, 1993.

Fikri Ahmad, "Arsitektur dan Benda-benda Seni" dalam Komisi Nasional Mesir untuk UNESCO, Sumbangan Islam kepada Ilmu dan Kebudayaan, terj. M. Tafsir, Bandung: Pustaka, 1986.

Hamka, Tafsir al-Azhar, Juz X, Jakarta: Pustaka Panjimas, t.th.

Husain, Abdul Karim, Seni Kaligrafi Khath Naskbi, Tuntunan Menulis Halus Huruf Arab dengan Metode Komparatif, Jakarta: Pedoman Ilmu Jaya, t.th.

Machasin, "Kaligrafi Sebagai Simbol Budaya Islami" Makalah Diskusi Panel Kaligrafi Islami Nasional, Yogyakarta: Panitia MTQ XVI, 1991.

Nasr, Sayyed Hossein, Spiritualitas dan Seni Islam, terj. Sutejo, Bandung: Mizan, 1993.

Oloan Situmorang, Seni Rupa Islam, Pertumbuban dan Perkembangannya, Bandung: Aksara, 1993.

Qalqashandi, Abū al-'Abbās Aḥmad ibn 'Ali, Subḥ al-Asba, Kairo: Wazarah al-Thaqafah wa al-Irshād al-Qaumi, t.th.

Reynold A Nicholson, Jalaluddin Rumi, Ajaran dan Pengalaman Sufi, terj. Sutejo, Jakarta: Pustaka Firdaus, 1996. 
Islah Gusmian

Safadi, Yasin Hamid, Kaligrafi Islam, terj: Abdul Hadi WM, Jakarta: PT. Pantja Simpati, 1986.

Schimmel, Annemarie, Dimensi Mistik dalam Islam, terj. Sapardi Djoko Damono dkk., Jakarta: Pustaka Firdaus, 1986.

Suwarsono, Pameran Kaligrafi Islam Indonesia, pada Muktamar Media Massa Islam Se-dunia I, 1980.

The Encyclopedia of Religion, New York: Macmilian Al-Publishing, 1987.

Wiyoso Yudoseputro, Pengantar Seni Rupa Islam di Indonesia, Bandung: Angkasa, 1986. 